\title{
Correction to: Effect of Cu Doping on the Structural and Electrochemical Performance of $\mathrm{LiNi}_{1 / 3} \mathrm{Co}_{1 / 3} \mathrm{Mn}_{1 / 3} \mathrm{O}_{2}$ Cathode Materials
}

\author{
LI YANG, ${ }^{1,2}$ FENGZHANG REN, ${ }^{1,3}$ QIGAO FENG, ${ }^{2,4}$ GUANGRI XU, ${ }^{2}$ \\ XIAOBO LI, ${ }^{2}$ YUANCHAO LI, ${ }^{2}$ ERQING ZHAO, ${ }^{2}$ JINGJING MA, ${ }^{2}$ \\ and SHUMIN FAN ${ }^{2}$ \\ 1.-Postdoctoral Research Station, School of Materials Science and Engineering, Henan \\ University of Science and Technology, Luoyang 471023, China. 2.-Henan Institute of Science \\ and Technology, Xinxiang 453003, China. 3.-e-mail: fengzhangr@163.com. 4.-e-mail: \\ syzxhome@163.com
}

\section{Correction to:}

\section{Journal of ELECTRONIC MATERIALS,} Vol. 47, No. 7, 2018

https://doi.org/10.1007/s11664-018-6284-8

In the original article, Fengzhang Ren's and Jingjing Ma's first names are spelled wrong. They are correct as shown here.
Publisher's Note Springer Nature remains neutral with regard to jurisdictional claims in published maps and institutional affiliations. 